\title{
Extending the Phenotype and Identification of a Novel Candidate Gene for Immunodeficiency in $5 q 11$ Microdeletion Syndrome
}

\author{
Veronica Arora $^{a}$ Shruti Aggarwal $^{a}$ Sunita Bijarnia ${ }^{a}$ Meena Lall $^{a}$ Anju Joshia \\ Ratna Dua-Puria Umang Arorab Ishwar Verma ${ }^{a}$

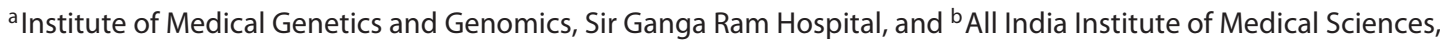 \\ New Delhi, India
}

\section{Established Facts}

- To date, only 13 cases of 5q11.2 microdeletion are reported. However, the phenotype is not precisely delineated. Features described so far are intellectual disability, dysmorphism, nonspecific ocular anomalies, and heart defects.

- DHX29 is the causative gene for developmental delay, dysmorphism, and heart defects. It encodes for an ATP-dependent RNA helicase, which is involved in initiation of translation.

\section{Novel Insights}

- The present case extends the phenotypic spectrum of 5q11.2 microdeletion with immunodeficiency, skeletal asymmetry, joint laxity, hypoplastic nares, and agenesis of corpus callosum.

- A common critical region spanning 1.4 Mb (54-55.4) and involving 14 genes has been defined for all the published cases.

- We propose that haploinsufficiency of IL6ST accounts for the immunodeficiency observed in these patients, as it plays a critical role in both innate and adaptive immunity.

\section{Keywords}

Common critical region · IL6ST · Immunodeficiency · $5 q 11$ microdeletion syndrome

\begin{abstract}
Array CGH has led to the delineation of innumerable microdeletion syndromes. We present a patient with a 7-Mb deletion at 5q11.2 with previously unreported features, such as immunodeficiency, asymmetry of hands and feet, joint laxity, and agenesis of corpus callosum. The clinical features of this patient are compared with 13 patients reported previ-
\end{abstract}

\section{KARGER}

(C) 2018 S. Karger AG, Basel ously. A common critical region (CCR) of 1.4 Mb (54-55.4 Mb) is defined in all cases including the present one. Of the 14 genes present in CCR, IL6ST is proposed to be the candidate gene for immunodeficiency observed in some of these patients. IL6ST encodes gp130, a signal transduction protein for various interleukins and cytokines. It is involved in the generation of both $\mathrm{T}$ and $\mathrm{B}$ lymphocytes as well as the production of acute-phase reactants. Microdeletion $5 q 11.2$ should be considered as a recognisable syndrome based on the common phenotype and the novel features described.

(c) 2018 S. Karger AG, Basel 
Whole-genome microarray has revolutionised the field of cytogenetics, leading to the delineation of innumerable microdeletion syndromes [Slavotinek, 2008]. In cases with developmental delay and/or dysmorphism, it has replaced conventional FISH and karyotype studies and is now considered the first-line investigation [Miller et al., 2010]. Prescott et al. [2005] first described 5q11.2 microdeletion syndrome in a patient with short stature, learning difficulties, tetralogy of Fallot, bifid uvula, and velopharyngeal defects. Subsequently, it was reported in 12 other patients with dysmorphism, varying degrees of intellectual disability, and nonspecific ocular defects (hypermetropia, esotropia, and myopia). In 2 of these patients, the phenotype resembled CHARGE syndrome. Haploinsufficiency of DHX29 is implicated as the culprit gene for the phenotypic characteristics of this syndrome. It encodes an ATP-dependent RNA helicase that is involved in the initiation of RNA translation and cell proliferation. [Snijders Blok et al., 2014]. Later, 2 more genes (SLC38A9 and GP1B1) were linked to the genesis of this phenotype [Fontana et al., 2016], of which SLC38A9 is present in the common critical region (CCR) defined in the present study.

Herein, we describe a 15-year-old girl with dysmorphic features, immunodeficiency, and learning difficulties, who was found to harbour a 7.5-Mb deletion at chromosome 5q11.2. This report also compares the clinical and molecular features of previously published cases. CCR for all the cases is defined, and IL6ST is proposed as the candidate gene for immunodeficiency.

\section{Case Report}

A 15-year-old girl, the second born to nonconsanguineous parents, was referred for evaluation of facial dysmorphism, poor scholastic performance, and recurrent infections. She was delivered at 38 weeks of gestation by caesarean section, carried out in view of foetal distress. Antenatal and perinatal periods were uneventful. She cried immediately after birth, and the APGAR score at $5 \mathrm{~min}$ was 9 . The anthropometry at birth was appropriate for age. Her weight was $2,885 \mathrm{~g}$ (15-50th centile), length $51 \mathrm{~cm}$ (50-85th centile), and head circumference $34 \mathrm{~cm}$ (15-50th centile) as per WHO growth charts. Dysmorphism and developmental delay were first noted at 2 years of age. All developmental milestones were found to be delayed: she achieved sitting independently at 14 months, walking at 23 months, and spoke her first sentences at 33 months of age; she was reported to be a slow learner at school. There is a history of recurrent respiratory tract and ear infections since infancy. She suffered from 4 episodes of lower respiratory tract infections in the past year, 3 and 5 episodes in 2016 and 2015, respectively. Strabismus was noted in the left eye at the age of 3 years. On evaluation, she was found to have hypermetropia and needed glasses. At present, she is in the 5th grade in school, interacts well with peers but has a below average scholastic performance.

On examination, she was alert and interactive. She was noted to have a long face, sloping forehead, strabismus, hypertelorism, hirsutism, underdeveloped ala nasi, prominent cheeks and philtrum, micrognathia, and a downturned mouth (Fig. 1A-C). Asymmetry was noted in the hands and feet, the right side being longer than the left by $2.5 \mathrm{~cm}$ (Fig. 1D, E). Hyperlaxity of the joints was present. Evaluation of higher mental functions revealed poor sustained attention and long-term memory as well as the inability to perform simple calculations. A convergent squint was observed, but there was no nystagmus or oculomotor apraxia. Her head circumference was $51 \mathrm{~cm}$ (50th centile), height $160.5 \mathrm{~cm}$ (50-75th centile), weight $35 \mathrm{~kg}(<3 \mathrm{rd}$ centile), and arm span $162 \mathrm{~cm}$, as per WHO charts. All other systemic examination parameters were within normal limits.

\section{Methods and Results}

A haemogram revealed haemoglobin to be $13.2 \mathrm{~g} / \mathrm{dL}$ (11.5-15 g/dL), packed cell volume $39.8 \%$, RBC count 4.33 million $/ \mathrm{mm}^{3}, \mathrm{MCH} 30.5 \mathrm{pg} / \mathrm{dL}, \mathrm{MCHC} 33.2 \mathrm{~g} / \mathrm{dL}$, RDW $12.3 \%$, and platelet count $100,000 / \mathrm{mm}^{3}$. The total leucocyte count was 3,900 cells $/ \mu \mathrm{L}$ (normal range 4,00011,000). The differential leucocyte count showed decreased lymphocytes with eosinophilia (neutrophils $68 \%$, lymphocytes $16 \%$, monocytes $6 \%$, eosinophils $9 \%$, and basophils $1 \%$ ). In view of recurrent infections, her immunological profile showed low IgG titres of $121 \mathrm{mg} /$ dL (716-1,711 mg/dL), low IgA $25 \mathrm{mg} / \mathrm{dL}$ (47-249 mg/ $\mathrm{dL}$ ), normal IgM $45 \mathrm{mg} / \mathrm{dL}$ (23-259 mg/dL), high IgE $920 \mathrm{IU} / \mathrm{mL}(150-300 \mathrm{IU} / \mathrm{mL}), \mathrm{CD} 4+\mathrm{T}$ cells $44 \%$ (27$53 \%), \mathrm{CD} 8+\mathrm{T}$ cells $18 \%$ (14-44\%), CD19+ B cells $3 \%$ (8-27\%), and CD16+CD56+ NK cells $0.5 \%$ (2-27\%). The immune profile was performed at 3 different times and showed a similar pattern (Table 1). A sputum culture done for recurrent lower respiratory tract infections showed gram positive diplococci, Streptococcus pneumoniae (on 3 occasions) and Haemophilus influenzae (on 2 occasions).

The girl was tested in view of developmental delay. TSH $3.2 \mathrm{mIU} / \mathrm{mL}(0.3-5 \mathrm{mIU} / \mathrm{mL}$ ), free T4 $4.3 \mathrm{ng} / \mathrm{dL}$ (4$12 \mathrm{ng} / \mathrm{dL}$ ), dried blood spot acylcarnitines, and urine organic acid analysis were within the normal range. A formal assessment revealed an IQ of 53, indicating mild intellectual disability.

Radiographs of the hands and feet were consistent with the asymmetry observed on clinical examination. The right side was longer than the left side by $2.5 \mathrm{~cm}$ in both the upper and lower limbs. Brain MRI showed cerebral atrophy and partial agenesis of the corpus callosum 

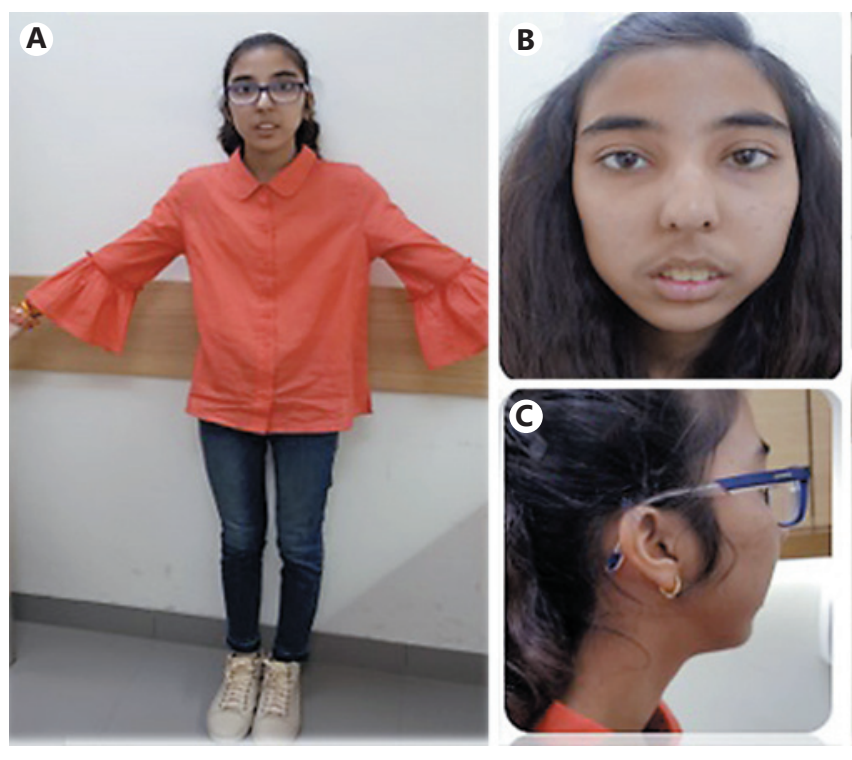

Fig. 1. A-C Clinical photographs of the patient showing tall and slender build, long face, hirsutism, hypertelorism, strabismus, sloping forehead, underdeveloped ala nasi, long prominent philtrum, micrognathia, and a downturned mouth. D, E Asymmetry of
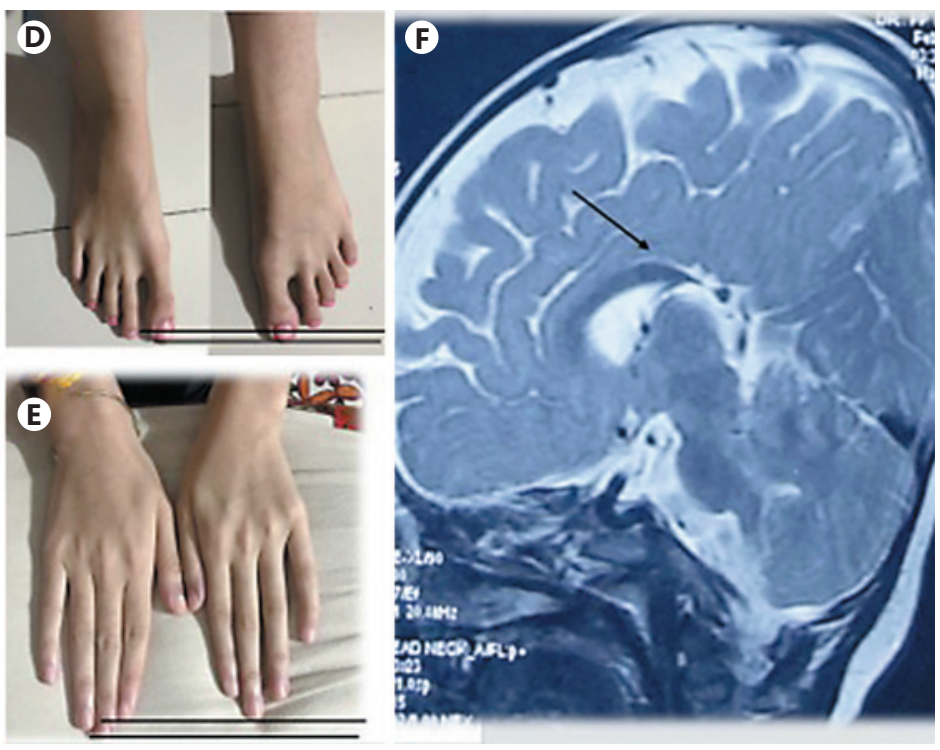

the hands and feet. Note the right side is longer than the left. F MRI image: sagittal plane, cerebral atrophy and absent splenium of corpus callosum (arrow) are shown.

Table 1. Immune markers done in 4 consecutive years

(Fig. 1F). Echocardiography and ultrasonography of the abdomen did not reveal any abnormalities.

In view of dysmorphism and developmental delay, a chromosomal aetiology was considered. The karyotype of the proband was 46,XX,del(5)(q11.2), consistent with a deletion in 5q11.2 (Fig. 2). Whole-genome microarraybased hybridisation was performed on an AGILENT $4 \mathrm{x} 180 \mathrm{~K}(\mathrm{CGH}+\mathrm{SNP})$ array slide and evaluation was done using cytogenomics software version 3.0.6.6 based on UCSC build 37 (hg19). It revealed a clinically significant 7.5- $\mathrm{Mb}$ deletion at 5q11.2q12.1 starting from 54,097,755 to $61,138,711$ bp in chromosome 5 (Fig. 3). No other copy number variations or regions of loss of heterozygosity were observed. The karyotypes of the father and the mother were normal, and there were no balanced rearrangements. Array-CGH study in the parents did not reveal any copy number changes, thus proving the de novo nature of the deletion.

\section{Discussion}

To date, only 13 cases of the microdeletion $5 \mathrm{q} 11.2$ have been reported (Table 2). We present a 15-year-old girl with a de novo 7.5-Mb deletion involving a large part of the 5q11.2 region. Although a distinct phenotype is

\begin{tabular}{lllll}
\hline & $\begin{array}{l}\text { January } \\
2015\end{array}$ & $\begin{array}{l}\text { August } \\
2016\end{array}$ & $\begin{array}{l}\text { May } \\
2017\end{array}$ & $\begin{array}{l}\text { February } \\
2018\end{array}$ \\
\hline TLC (cells/ $\mu \mathrm{L})$ & 4,100 & 3,750 & 3,900 & 4,050 \\
Differential leucocyte count & & & & \\
$\quad$ N & 62 & 67 & 68 & 60 \\
L & 15 & 13 & 16 & 14 \\
M & 8 & 5 & 6 & 10 \\
E & 13 & 10 & 9 & 14 \\
B & 2 & 0 & 1 & 2 \\
Immunoglobulins & & & & \\
IgG (range 716-1,711 mg/dL) & 96 & 108 & 121 & 77 \\
IgA (range 47-249 mg/dL) & 14 & 17 & 25 & 11 \\
IgM (range 23-259 mg/dL) & 28 & 23 & 45 & 21 \\
IgE (range 150-300 IU/mL) & 442 & 1,020 & 920 & 904 \\
CD4+ T (range 27-53\%) & 22 & 18 & 44 & 22 \\
CD19+ (range 6-27\%) & 2 & 1.5 & 3 & 2.8 \\
NK cells (range 2-27\%) & 0.2 & 0.8 & 0.5 & 0.9 \\
\hline
\end{tabular}

TLC, total leucocyte count. not defined for this microdeletion syndrome, published cases share many common clinical characteristics (Table 2). The proband has some overlapping features with the previously reported cases, including intellectual disability, ocular defects, sloping forehead, low-set posteri-
Arora/Aggarwal/Bijarnia/Lall/Joshi/ Dua-Puri/Arora/Verma 


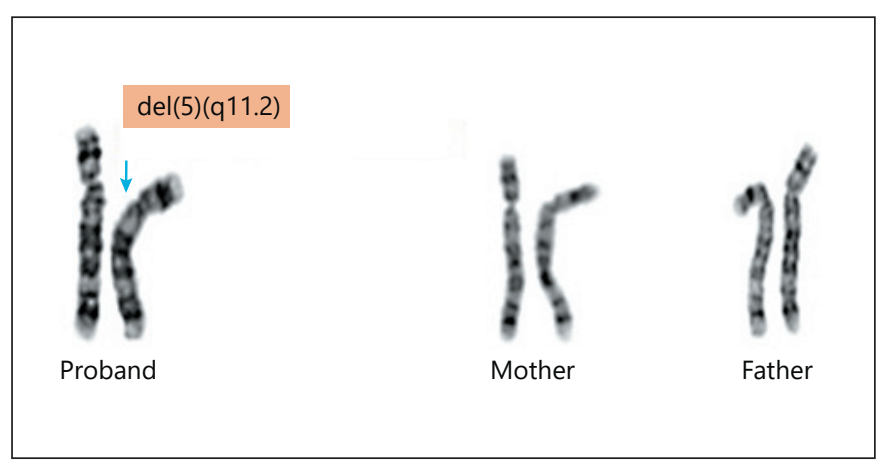

Fig. 2. Chromosome 5 of the proband showing the $5 \mathrm{q} 11.2$ deletion (left), and the normal chromosomes of the mother (middle) and the father (right).

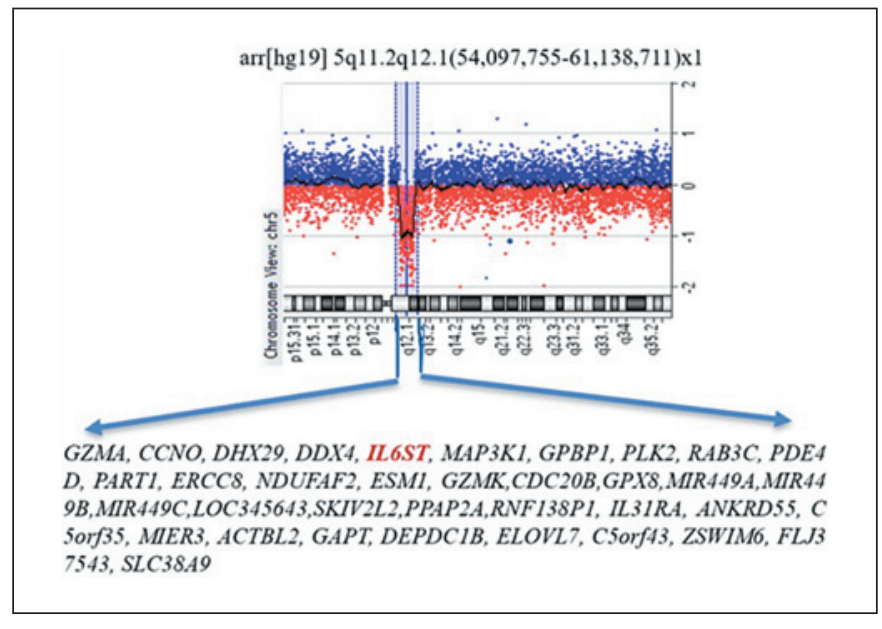

Fig. 3. Microarray image showing the $7.5-\mathrm{Mb}$ deletion together with the genes in this region.

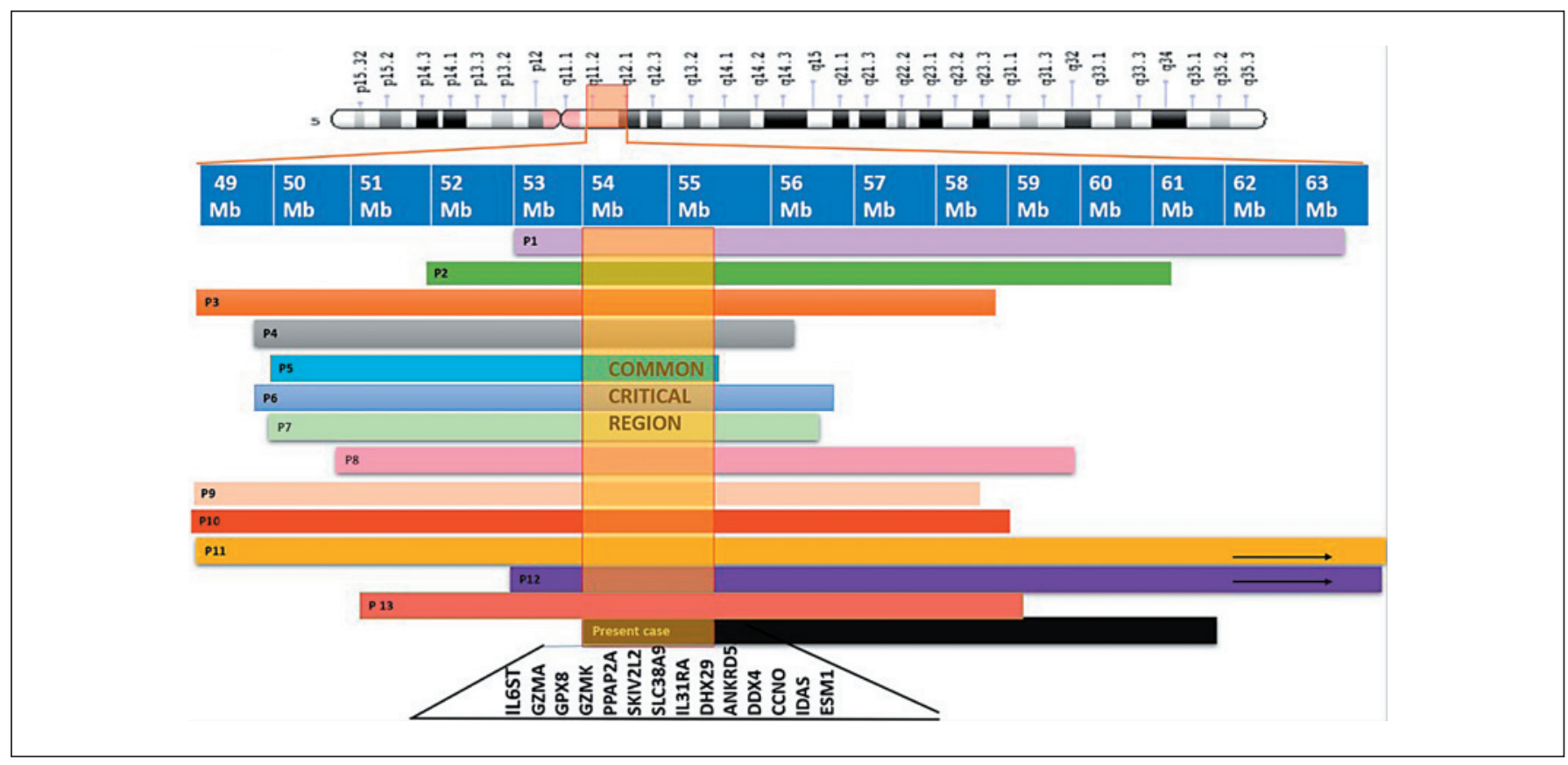

Fig. 4. Chromosome $5 \mathrm{q} 11$ deletion for all the reported patients as well as the present case. The common critical region is highlighted (54-55.4 Mb), and the genes located in this region are shown below.

orly rotated ears, micrognathia, and arachnodactyly. In addition, asymmetry in hands and feet, prominent maxillae, hypoplastic nares, and joint laxity were observed. Brain MRI showed the presence of partial agenesis of corpus callosum and cortical atrophy, which have not been previously reported in this microdeletion syndrome.

Candidate Gene in 5q11 Microdeletion Syndrome
CCR for all the previous cases spans from $54,097,755$ to $55,412,230 \mathrm{bp}$ and contains 14 OMIM genes (Fig. 4). DHX29 encodes a DExH-box protein that is required for the translation of mRNAs with structured $5^{\prime}$ UTRs. It is important for initiation of translation and cell proliferation. Silencing of this gene has been implicated as the main contributor to the dysmorphisms, as well as growth

Mol Syndromol 2018;9:312-318 


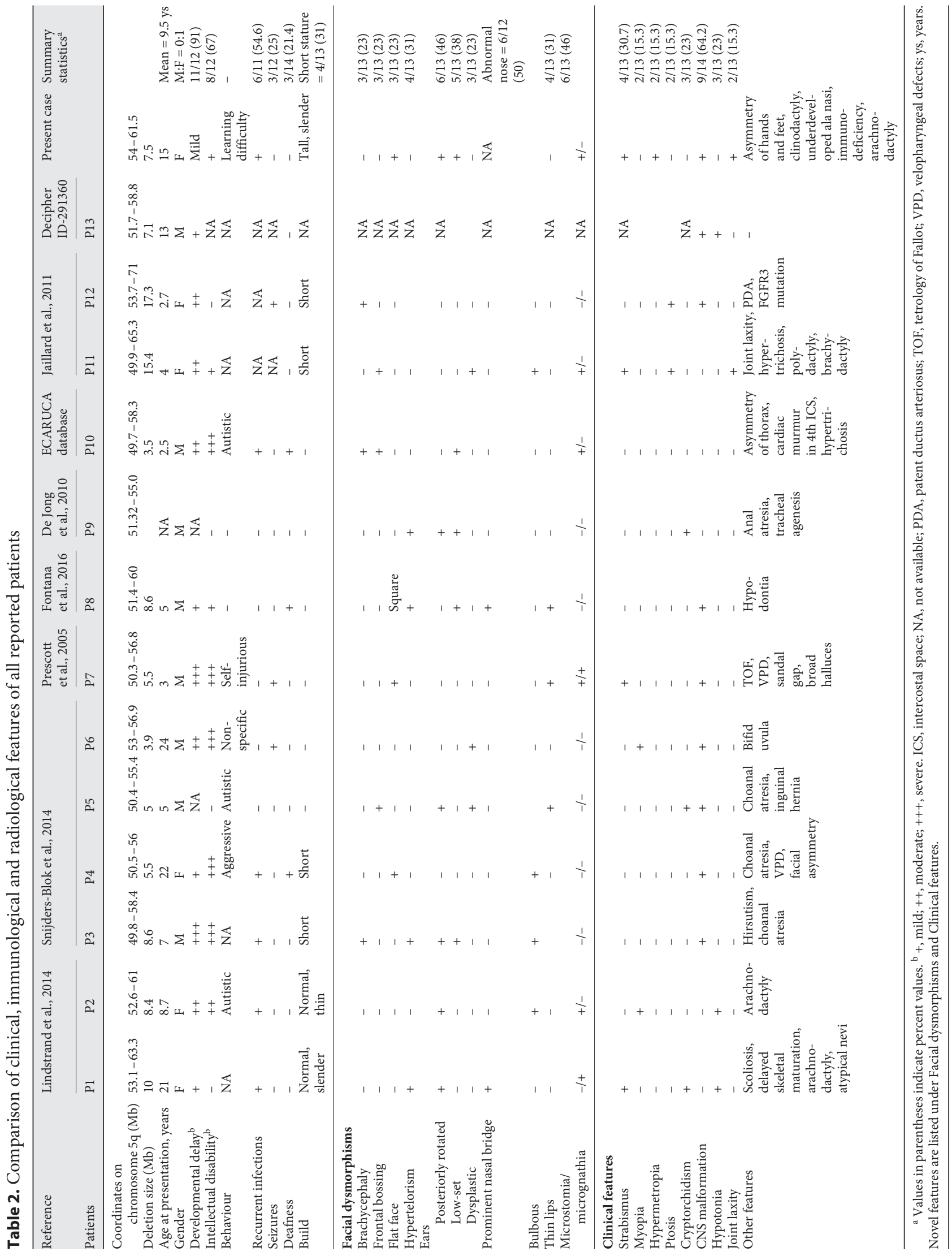


deficiencies, seen in some of these patients [Snijders Blok et al., 2014].

The proband had symptoms consistent with immunodeficiency. Testing revealed a deficiency of both humoral and cellular immunity, which included reduced levels of immunoglobulins (IgG and IgA), T cells, and markedly decreased B and NK cells. There was mild eosinophilia. The deleted region in chromosome $5 \mathrm{q} 11$ contains 45 genes, amongst which IL6ST is identified as the probable gene related to immunodeficiency due to its established role in immune responses. The protein encoded by this gene is a signal transducer shared by many cytokines, including interleukin 6 (IL-6), ciliary neurotrophic factor, leukaemia inhibitory factor, and oncostatin M. This protein functions as a part of the cytokine receptor complex [Tanaka et al., 2014; Schwerd et al., 2017]. It has also been called the B-cell stimulatory factor 2 (BSF-2), based on the ability to induce differentiation of activated B cells into antibody-producing cells, especially IgG producing IL-21 [Hirano et al., 1986; Ma et al., 2012]. Furthermore, IL6 has a prominent role in synthesis and secretion of acute-phase reactants, which have multiple and complex roles in integrated host defences against bacterial pathogens such as Klebsiella pneumoniae and Streptococcus pneumoniae [Quinton et al., 2009]. Thus, the recurrent respiratory tract infections in this patient can be explained by a poor humoral immune response.

Defective IL6 signalling due to haploinsuffiency of IL6ST could play an important role in the pathogenesis of the immunodeficient state. In addition, recurrent infections have been previously described in 4 patients with 5q11.2 microdeletion syndrome, and all 4 were haploinsufficient for this gene (55.23-55.29 Mb), thus substantiating this hypothesis. Furthermore, Schwerd et al. [2017] presented a patient with recurrent infections, eczema, bronchiectasis, high IgE, eosinophilia, defective B cell memory, and an impaired acute-phase response. The patient was found to have a homozygous loss-of-function mutation of IL6ST (encoding gp130 p.N404Y). The present study confirms the disease-causing role of this gene. The more severe phenotype in the patient described by Schwerd et al. [2017] compared to that in the present study is probably due to the bi-allelic mutation in their case, which resulted in complete abolition of protein production and function.

In summary, we report a patient with a $5 \mathrm{q} 11.2$ microdeletion and novel features of immunodeficiency, asymmetry of hands and feet, and agenesis of corpus callosum, thus extending the phenotypic spectrum of this rare microdeletion syndrome. Though the microdeletion is larger than CCR, these features have not been previously reported including the patients with deletions beyond the 5q11 region. Microdeletion 5q11.2 should be considered a recognisable microdeletion syndrome, based on the previously described and the newly added features, with 54-55.4 Mb being the CCR. We also emphasise the need for neurological, immune, and skeletal system examination in these patients. IL6ST is proposed to be the candidate gene for immunodeficiency due to its critical role in immune regulation. However, further characterisation of immune functions in additional patients with $5 \mathrm{q} 11 \mathrm{mi}-$ crodeletion is required to validate this hypothesis.

\section{Statement of Ethics}

This study was approved by the ethics committee, and written informed consent was obtained.

\section{Disclosure Statement}

All the authors declare no conflicts of interest.

\section{References}

De Jong EM, Douben H, Eussen BH, Felix JF, Wessels $\mathrm{M}$, et al: $5 \mathrm{q} 11.2$ deletion in a patient with tracheal agenesis. Eur J Med Genet 18: 1265-1268 (2010).

Fontana P, Tortora C, Petillo R, Falco M, Miniero $\mathrm{M}$, et al: A novel $5 \mathrm{q} 11.2$ microdeletion in a child with mild developmental delay and dysmorphic features. Am J Med Genet A 170: 2445-2448 (2016).

\footnotetext{
Hirano T, Yasukawa K, Harada H, Taga T, Watanabe $Y$, et al: Complementary DNA for a novel human interleukin (BSF-2) that induces B lymphocytes to produce immunoglobulin. Nature 324:73-76 (1986).

Jaillard S, Andrieux J, Plessis G, Krepischi AC, Lucas J, et al: $5 q 12.1$ deletion: delineation of a phenotype including mental retardation and ocular defects. Am J Med Genet A 155A:725731 (2011).
}

\footnotetext{
Lindstrand A, Grigelioniene G, Nilsson D, Pettersson M, Hofmeister W, et al: Different mutations in PDE4D associated with developmental disorders with mirror phenotypes. J Med Genet 51:45-54 (2014).

Ma CS, Deenick EK, Batten M, Tangye SG: The origins, function, and regulation of $\mathrm{T}$ follicular helper cells. J Exp Med 209:1241-1253 (2012).
}

Candidate Gene in 5q11 Microdeletion Syndrome
Mol Syndromol 2018;9:312-318 DOI: $10.1159 / 000494995$ 
- Miller DT, Adam MP, Aradhya S, Biesecker 1, Brothman AR, et al: Consensus statement: chromosomal microarray is a first-tier clinical diagnostic test for individuals with developmental disabilities or congenital anomalies. Am J Hum Genet 86:749-764 (2010).

Prescott K, Woodfine K, Stubbs P, Super M, Kerr B, et al: A novel $5 \mathrm{q} 11.2$ deletion detected by microarray comparative genomic hybridisation in a child referred as a case of suspected 22q11 deletion syndrome. Hum Genet 116: 83-90 (2005).
Quinton LJ, Jones MR, Robson BE, Mizgerd JP: Mechanisms of the hepatic acute-phase response during bacterial pneumonia. Infect Immun 77:2417-2426 (2009).

-Schwerd T, Twigg SRF, Aschenbrenner D, Manrique $\mathrm{S}$, Miller KA, et al: A biallelic mutation in IL6ST encoding the GP130 co-receptor causes immunodeficiency and craniosynostosis. Exp Med 214:2547-2562 (2017).

-Slavotinek AM: Novel microdeletion syndromes detected by chromosome microarrays. Hum Genet 124:1-17 (2008).
Snijders Blok C, Corsten-Janssen N, FitzPatrick DR, Romano C, Fichera M, et al: Definition of 5 q11.2 microdeletion syndrome reveals overlap with CHARGE syndrome and 22q11 deletion syndrome phenotypes. Am J Med Genet A 164A:2843-2848 (2014).

Tanaka T, Narazaki M, Kishimoto T: IL-6 in Inflammation, immunity, and disease. Cold Spring Harb Perspect Biol 6:a016295 (2014). 